\title{
Cerebral Ischemia
}

\author{
Ryszard Pluta, MD, PhD
}

Editor

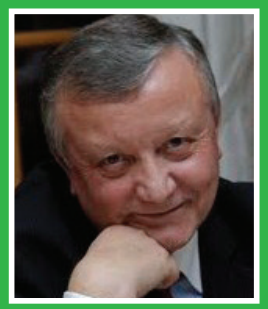

Professor Ryszard Pluta, MD, PhD, is the head of the Laboratory of Ischemic and Neurodegenerative Brain Research, Mossakowski Medical Research Institute, Polish Academy of Sciences, Warsaw, Poland. He has held positions at the National Institutes of Health, Bethesda, USA, at the Institute for Basic Research in Developmental Disabilities, Staten Island, USA, and at the Max-Planck Institute for Neurological Research in Cologne, Germany. Professor Pluta was awarded by the Polish Association of Neuropathologists, President of Polish Academy of Sciences, Medical Secretary of Polish Academy of Sciences, Batory's Foundation in Warsaw, Poland, International Brain Research Organization in Paris, France, and Alzheimer's Association Chicago, USA. In 2017, Professor Pluta was awarded the Maria Curie-Skłodowska statuette. In New York in 1994 he was the first to propose the ischemic etiology of Alzheimer's disease, followed by publications in which he presented proteomic and genomic alterations in the ischemic brain that are identical to those in Alzheimer's disease. In 1998, he was the first to present autoimmunization as a new therapy for Alzheimer's disease. Professor Pluta has published more than 250 peer-reviewed scientific articles and his current research focuses on developing ischemic model of Alzheimer's disease. He is listed among the top $2 \%$ outstanding scientists in the world.
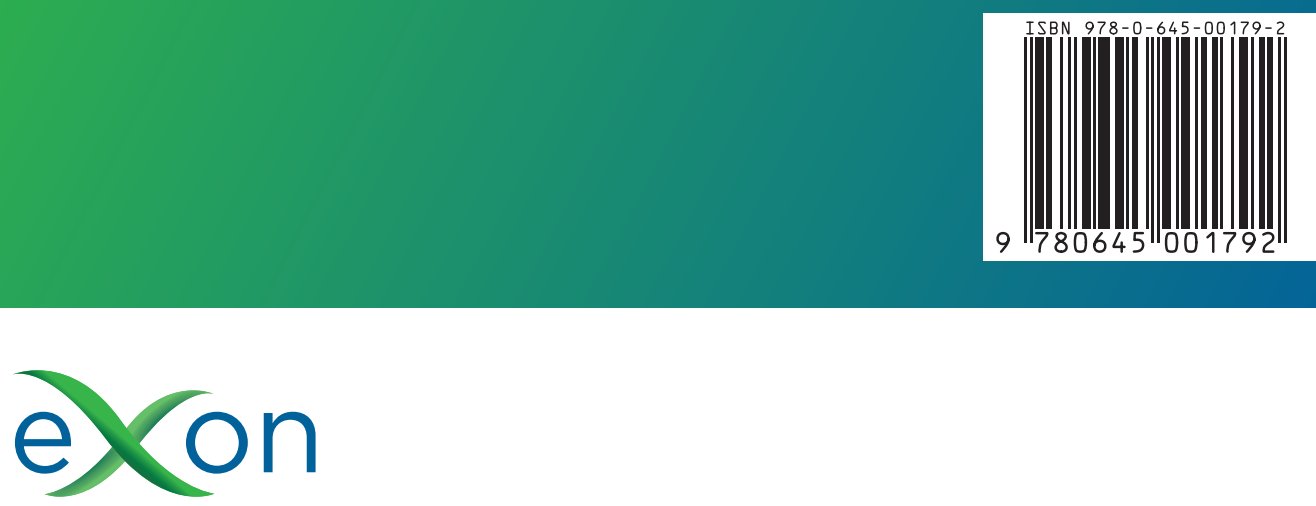

PUBLICATIONS 